\section{Fragilidades no cuidado em saúde às pessoas com desordens relacionadas ao glúten}

\author{
Weaknesses in healthcare for persons with \\ gluten-related disorders
}

Fragilidades en el cuidado de salud de personas
con desórdenes relacionados al gluten
Juliana Crucinsky 1,2
Jorginete de Jesus Damião ${ }^{1}$
Inês Rugani Ribeiro de Castro ${ }^{1}$

doi: 10.1590/0102-311X00244219

\section{Resumo}

As desordens relacionadas ao glúten (DRG) afetam de 1\% a 6\% da população, com complicações e alto risco de morbimortalidade em curto e longo prazos. Desde 2009, o Brasil possui um Protocolo Clínico de Diretrizes Terapêuticas para a Doença Celíaca, entretanto, são comuns as queixas das pessoas com DRG a respeito da falta de conhecimento dos profissionais de saúde nessa temática e das dificuldades relacionadas ao cuidado em saúde em relação tanto ao diagnóstico quanto ao tratamento. Este estudo objetivou compreender as fragilidades no cuidado em saúde percebidas por pessoas com DRG. Foi realizada uma pesquisa qualitativa virtual no grupo Viva Sem Glúten (VSG), da rede social Facebook, na qual foram consultados os registros armazenados no grupo por 65 meses, que totalizaram 510 postagens e seus respectivos comentários. Os dados foram agrupados em categorias, e foi realizada análise temática de conteúdo, adotando-se os referenciais teóricos sobre o cuidado em saúde. A análise revelou que as buscas por um diagnóstico e por tratamento adequado frequentemente são descritas como uma peregrinação, sendo decorrentes das fragilidades no cuidado em saúde, traduzidas pela falta de conhecimento atualizado dos profissionais sobre as DRG e por problemas na relação profissional-paciente. As fragilidades no cuidado em saúde e os diagnósticos tardios contribuem para aumentar o risco de complicações é óbitos. Nesse contexto, o grupo VSG se destaca em seu papel de grupo de apoio e rede de solidariedade, favorecendo o esclarecimento e o empoderamento de inúmeras pessoas com DRG.

Pesquisa Qualitativa; Relações Médico-Paciente; Grupos de Autoajuda

\author{
Correspondência \\ J. Crucinsky \\ Rua Ituverava 934, apto. 203, Rio de Janeiro, RJ 22750-006, \\ Brasil. \\ ju.crucinsky@gmail.com \\ 1 Universidade do Estado do Rio de Janeiro, Rio de Janeiro, \\ Brasil. \\ 2 Universidade Castelo Branco, Rio de Janeiro, Brasil.
}




\section{Introdução}

As desordens relacionadas ao glúten (DRG) incluem a doença celíaca, a sensibilidade ao glúten não celíaca, a ataxia do glúten, a dermatite herpetiforme e a alergia ao trigo ${ }^{1}$. Elas têm afetado um número cada vez maior de pessoas, inclusive em regiões mais pobres do mundo 2. A prevalência de doença celíaca é estimada em $1 \%$ da população, com maior predominância nas mulheres, enquanto a da sensibilidade ao glúten não celíaca, em $6 \%$ 1. Já para a alergia ao trigo (ou ao glúten), condição mais comum na infância, a prevalência é de 15\%-20\% em crianças 3 . Em relação à ataxia do glúten, estudo realizado na Inglaterra encontrou 132 casos em 224 pessoas avaliadas 3. A prevalência da dermatite herpetiforme é maior entre homens e varia entre os países, estimando-se um novo caso para cada milhão de habitantes por ano na Alemanha, 11:100.000 na Escócia, 20-39:100.000 na Suécia, 58,8:100.000 na Irlanda 3,4. Para todas as DRG, o tratamento consiste em dieta isenta de glúten e de contaminação por essa proteína, encontrada em cereais como trigo, centeio e cevada 1.

O diagnóstico das DRG, em geral, é tardio em função da pouca familiaridade dos profissionais de saúde com as manifestações da doença e/ou da falta de acesso aos recursos necessários para sua confirmação 5,6. Além disso, apesar de o tratamento das DRG ser relativamente simples, o dia a dia das pessoas com essas condições pode ser um constante desafio, com sérios impactos na saúde psicológica e no equilíbrio emocional 6,7. Isso é agravado pelas fragilidades no cuidado a essas pessoas, que incluem orientações dietéticas incorretas ou incompletas, falta de orientação a respeito da contaminação cruzada e banalização dos sinais e sintomas apresentados 6 .

A peregrinação em busca por tratamento é relatada por pessoas que convivem com outras doenças crônicas em que o acesso ao diagnóstico e ao tratamento não está disponível. Estudo com mulheres com endometriose evidencia várias formas de violência vivenciadas na peregrinação pelo acesso ao diagnóstico e tratamento 8 , como a invisibilidade de sua dor e a desqualificação de seu sofrimento, contribuindo para a negligência no cuidado à saúde 9 .

As dificuldades no percurso de diagnóstico e de cuidado em serviços de saúde fazem com que as pessoas com DRG busquem informações e apoio nas associações de celíacos, em páginas eletrônicas sobre o tema e em grupos existentes nas redes sociais 6 . Nesse contexto, o ambiente virtual ganha destaque como espaço em que pessoas com DRG, seus familiares e aquelas em busca de um diagnóstico se encontram para trocar informações e buscar o acolhimento que não encontram nos serviços de saúde.

Buscando dar visibilidade a essa realidade e subsidiar a qualificação da atenção à pessoa com DRG no Sistema Único de Saúde (SUS), nosso artigo pretende compreender as fragilidades no cuidado em saúde percebidas por pessoas com DRG.

\section{Percurso metodológico}

O estudo consistiu em uma pesquisa qualitativa virtual (pesquisa online) no grupo Viva Sem Glúten (VSG), alocado na rede social Facebook (https://www.facebook.com/groups/vivasemgluten/). Nesse tipo de pesquisa, diferentes recursos podem ser usados como fontes de dados, como as videoconferências, os sites de relacionamentos, trocas de informação em tempo real, assim como redes sociais e grupos de debates e comunidades online 10.

A comunicação nos espaços virtuais deixa registros que ficam armazenados e podem ser consultados, copiados e arquivados pelo pesquisador a qualquer momento, a partir de diversos mecanismos de busca oferecidos pela própria rede 5 , sendo aceitável citar as mensagens publicadas, desde que elas não sejam identificadas 11 . Tendo em vista que o presente estudo se baseia na análise de conteúdo de site público, não foi necessário submetê-la ao Comitê de Ética. Vale registrar que a pesquisa foi autorizada pela equipe de moderação, e os participantes foram informados de sua realização.

Na temática das DRG, o grupo VSG se destaca por ser a maior comunidade online brasileira, contando com quase 50 mil participantes na ocasião da pesquisa. Ele é um grupo público, existente apenas no ciberespaço, no qual os participantes escrevem espontaneamente seus relatos, pedidos de orientação e ajuda. É formado por celíacos, alérgicos ao trigo, sensíveis ao glúten, familiares, profissionais de saúde e produtores de alimentos sem glúten, oriundos de diferentes regiões do país e do exterior. 
A maior parte dos integrantes são mulheres com algum tipo de DRG ou companheiras de homens com essa condição ou, ainda, mães de crianças celíacas ou alérgicas, alfabetizadas (muitas com nível superior ou pós-graduação), com acesso frequente à Internet. As atividades desse grupo contemplam o acolhimento dos recém-chegados, o esclarecimento de dúvidas, o compartilhamento de informações e materiais diversos relacionados à temática das DRG e a divulgação de eventos sobre o assunto 6 .

A participação da autora principal do estudo (J.C.) no grupo foi fundamental para que, ao iniciá-lo, os temas de maior relevância já fossem conhecidos, assim como as queixas e os termos mais recorrentes nas postagens. Ela começou a participar do grupo VSG quando recebeu o diagnóstico de doença celíaca, tendo atuado como moderadora no grupo no período compreendido entre 2012 e 2015. Após 2015, a autora continuou a participar do grupo como integrante.

A produção de dados foi realizada dentro do grupo VSG no Facebook referente ao período compreendido entre 8 de setembro de 2011 a 20 de fevereiro de 2017, por meio do resgate de postagens em ordem cronológica decrescente. Esse resgate ocorreu no período entre 20 e 28 de fevereiro de 2017. Ressalta-se que, para o resgate das postagens, não houve interação entre as autoras e os participantes. Considerando que a comunicação nas redes sociais é dinâmica, sendo muito expressivo o volume de postagens e comentários, o Facebook limita o acesso a postagens mais antigas. Por esse motivo, não foi possível acessar registros anteriores à data inicial do período estudado.

Todas as postagens armazenados no feed de notícias do grupo foram agrupadas em um programa para edição de textos (Microsoft Word for Windows, versão 2016; https://products.office.com/), totalizando 1.552 postagens e 3.500 páginas. Esse material passou por uma leitura prévia para identificar e eliminar postagens repetidas, que continham assuntos fora do escopo deste trabalho e fotos dos participantes, resultando em um documento com 1.150 páginas com 510 postagens e seus respectivos comentários, sendo esse o "corpus de análise" 12. Foram selecionadas as postagens que continham palavras-chave referentes ao cuidado em saúde, no âmbito das DRG, a saber: anemia, ansiedade, anticorpo, biópsia, cálcio, câncer, complicações, consulta, dapsona, dentista, depressão, diagnóstico, dieta, doença celíaca refratária, endoscopia, enfermagem, enzimas, exames, ferro, glutamina, hospital, internação, linfoma, médico, nutrição, óbito, luto, osteopenia, osteoporose, peregrinação, peso, pânico, probióticos, psicologia, psiquiatria, remédio, sangue, sintomas, suplementação, tireoide, tratamento, vesícula, vitaminas.

Parte dessas palavras havia sido identificada para o estudo de Paula et al. 6, cuja temática era as fragilidades envolvendo os serviços de saúde no SUS, sob a ótica dos usuários. São palavras recorrentes nas falas dos participantes do grupo, que expressam preocupação com o conhecimento técnico dos profissionais e a expectativa quanto à atenção que esperam receber.

Para a análise dos dados, utilizou-se a técnica de análise de conteúdo, com ênfase na análise temática 12. A organização do material foi realizada com o auxílio do software NVivo, versão Starter (https://www.qsrinternational.com/nvivo/home), e envolveu a codificação do material e a classificação dos recortes em categorias temáticas, definidas durante a realização das etapas de pré-análise e de exploração do material 12,13. A análise foi organizada a partir dos seguintes eixos temáticos: (a) A Condição de Celíaco; (b) Peregrinação para Diagnóstico; (c) As Fragilidades no Cuidado em Saúde; e (d) O Grupo VSG como Rede de Apoio. A análise dos dados foi balizada pelos referenciais teóricos do Cuidado em Saúde 14,15,16,17,18,19 e da Antropologia Médica 20,21,22. De forma complementar, os estudos sobre itinerários terapêuticos contribuíram para a discussão acerca das experiências das pessoas com DRG em sua busca pelo diagnóstico 23,24,25.

\section{Resultados e discussão}

\section{A condição de celíaco}

O corpus de postagens, depoimentos e comentários coletados no grupo VSG forneceu um vasto material para análise e possibilitou traçar um panorama do que é (con)viver, no Brasil, com uma necessidade alimentar especial permanente que impõe adaptações e restrições ao cotidiano. O recém-diagnosticado (e/ou seus familiares) precisa rapidamente repensar suas práticas alimentares. A sobrevivência 
e a garantia da saúde dependem de muitas mudanças, não só na forma de se alimentar, com refeições preparadas em casa (já que comer em restaurantes e refeitórios se torna uma atividade de risco), mas também na escolha dos alimentos, na forma de prepará-los, de armazená-los e de cuidar da rotina familiar, incluindo a higienização de equipamentos e utensílios e a frequência de limpeza dos ambientes domésticos para evitar contaminações por glúten 7 . Tais mudanças geram grandes impactos na rotina e no âmbito emocional dessas pessoas:

(P1): "É muito difícil aceitar, ainda mais quando descobri na minha filha. Ela tinha 1 ano e 6 meses e, pensa, já estava acostumada a comer de tudo. Me doía ver ela pedir bilaia [bolacha], carrão [macarrão] e não poder dar".

(P3): “...muitas vezes, ver os outros comendo e não poder comer é motivo de me trancar no quarto e chorar a tarde inteira...".

Uma dieta de exclusão tem impactos na vida familiar, na vida social, escolar e profissional também, pois o próprio ambiente pode ser um local de insegurança, devido ao risco de contaminações 7,10. Assim, são necessárias mudanças e adaptações em todas as situações envolvendo comida, como almoços e jantares de família, aniversários, viagens e passeios. Entretanto, nem todas as famílias conseguem compreender e se adaptar.

(P4): “... a contaminação é muito fácil de acontecer, aqui em casa então... ninguém é celíaco, e a única pessoa que toma cuidado é a minha mãe, porém ainda não é o 100\% ideal...".

$\mathrm{O}$ trigo carrega consigo profundos simbolismos, sendo considerado um alimento sagrado em diversas culturas 26. Para algumas pessoas, é difícil assimilar o fato de que, em vez de alimento santo, ele é nocivo e precisa ser evitado.

À exceção da dermatite herpetiforme, não existem lesões visíveis, e as manifestações das DRG podem ser subjetivas. Isso dificulta a identificação da gravidade dos sintomas e leva à banalização das queixas, do mal-estar e do cansaço, frequentemente atribuídos a "exagero" ou "hipocondria", principalmente quando relatadas pelas mulheres. Suas queixas são desqualificadas de forma similar ao que as mulheres com endometriose vivenciam 8,9 .

(p7): “...todos meus parentes acham que é frescura, todos. Tanto que falam 'come', só isso, vai', 'não faz mal', 'só hoje”".

Além disso, as mulheres estão mais expostas a riscos de contaminação, quando seus familiares não abrem mão dos alimentos contendo glúten e quando o preparo de dois tipos de comida é rotina:

(P11): “...A minha médica falou que tenho que mudar a minha vida porque o meu caso está muito sério perigo de [ter] câncer (...). Mas aí meu marido e filho querem comer macarrão... pizza [com glúten]... Quando falo de contaminação cruzada falam que é exagero".

Os problemas de relacionamento se agravam quando a condição clínica interfere na vida profissional e na renda familiar:

(P15): “...sou técnica em enfermagem e trabalho há oito anos cuidando de pacientes em domicílio. (...) A família pede (...), quando você vê, está preparando refeições para toda a família, limpando cozinha e outros serviços domésticos mais. (...) Mas com o agravamento de minha doença somente descobri a doença celíaca há um ano e sou dermatite herpética (...). Tomei coragem, sai do trabalho há 40 dias e minha saúde nunca esteve tão bem. Mas as contas chegam, o dinheiro acabou (...). Meu marido está me tratando mal, muito mal. Diz que estou exagerando, que minha alergia é ao trabalho".

Sobre as mulheres recai a responsabilidade de cuidar e educar os filhos 27 e, mais ainda, quando eles apresentam alguma condição adversa relacionada à saúde. As mães de crianças com doenças graves são estigmatizadas como se fossem culpadas pela situação da criança. Elas são colocadas na condição de principais responsáveis por seus cuidados e sobrevivência 28. Assim, quando são os filhos que apresentam as DRG, na maioria das vezes, a mãe, além do ônus do cuidado solitário e redobrado, sente-se responsável por ter "transmitido" a doença para o filho e/ou se sente culpada quando a criança não responde bem ao tratamento.

(P16): "Não eu não pedi um filho alérgico alimentar e nem ele pediu pra ser assim, apenas é".

(P17): "Hoje o M. teve a consulta de acompanhamento com a gastro, e fiquei pasma quando ela disse q ele ganhou apenas $140 \mathrm{~g}$ em 2 meses... Pensem na minha tristeza, ele está comendo bem, comida caseira, livre de glúten, mas não está ganhando peso suficiente... A gastro encaminhou ele pra hematologista e pra geneticista, por quê? (...) O que pode ser? Fiz algo errado?”. 


\section{Peregrinação para diagnóstico}

Entre o momento em que a pessoa (ou familiar) percebe que há algo errado, busca atendimento e recebe o tratamento correto, há um hiato de tempo que depende de muitos fatores, como a percepção da pessoa a respeito de seus sintomas, seu conhecimento sobre tratamentos e serviços existentes, o acesso a eles e suas condições socioeconômicas 17 , além daqueles relacionados ao cenário de uma rede de saúde que não está adequadamente estruturada para o cuidado a essas pessoas ${ }^{4}$. Em relação às DRG, percebe-se que o itinerário terapêutico inclui a busca de informações por meio das redes sociais, de vídeos no YouTube e leituras em blogs e por tentativas de solução por conta própria.

Dentro do VSG, há várias histórias de pessoas que passaram muito tempo peregrinando em busca de um diagnóstico: anos convivendo com dores, desconfortos e com a incerteza do que se tem, processo que, muitas vezes, culmina em sérias complicações à saúde.

Toda essa peregrinação prolonga a dor, a angústia e o sofrimento das pessoas com DRG e seus familiares, de uma forma semelhante à relatada por Valdanha-Ornela \& Santos 25 em relação a adolescentes com anorexia nervosa e relatada previamente por Paula et al. 6 para celíacos. Chamam atenção os relatos sobre complicações e sofrimento decorrentes do diagnóstico tardio, como inúmeras gestações perdidas, pessoas que ficaram hospitalizadas entre a vida e a morte e óbitos, inclusive entre pessoas jovens:

(P45): "Fui diagnosticada menos de dois anos atrás, e considero que tive o privilégio de poder voltar a viver. Meus primeiros sintomas apareceram quando eu tinha 1 ano, tive sérios episódios de dermatite herpetiforme, problemas gástricos e ósseos, mas em uma cidade de 5 mil habitantes (onde cresci) a doença celíaca era e é desconhecida e não diagnosticada...”.

(P13): “...Eu perdi 9 fetos no começo da gestação por causa da celíaca...”.

O caso de uma jovem participante do VSG, que veio a óbito aos 21 anos por sepse, após muitas complicações relacionadas à doença celíaca, mobilizou o grupo, merecendo postagens de diferentes pessoas. De acordo com os relatos, seus sintomas iniciaram ainda na infância, porém seu diagnóstico só foi fechado na adolescência. Mesmo tendo acesso a orientações por meio do PROACEL, grupo de assistência aos celíacos ligado à Universidade Federal do Pará, e fazendo a dieta corretamente, seu quadro evoluiu para doença celíaca refratária.

Em diversos municípios, faltam especialistas, e o tempo de espera até conseguir uma consulta pode chegar a seis meses ou até anos. Há realidades em que a oferta de exames é inexistente ou restrita tanto na rede pública quanto na rede privada de saúde:

(P57): "Minha irmã está no posto médico na cidade de Nova Lima [Minas Gerais] e pediu à médica os exames de sorologia. A médica passou os exames, mas a prefeitura não autoriza, disseram que é para fazer particular...".

(P60): "O meu plano não autorizou o IgG antigliadina e o anti-transglutaminase (...) tive que pagar particular!".

Dentre as pessoas que têm plano de saúde, há relatos de busca por consultas particulares não cobertas por ele após experiências mal sucedidas com profissionais credenciados que não tinham conhecimento suficiente sobre as DRG.

(P14): "Já fui na única que aceita o plano aqui na minha cidade, ela [nutricionista] foi atenciosa, mas deu para perceber que não entende muito não. Agora verificando se encontro alguma em uma cidade próxima (65km). Se não vou ter que pagar particular em uma que já ouvi falar que é muito boa, mas só no dinheiro".

O Protocolo Clínico e Diretrizes Terapêuticas para Doença Celíaca (PCDTDC), publicado pelo Ministério da Saúde, prevê a realização dos exames para diagnóstico da doença celíaca nas unidades do SUS, com definição dos serviços de referência e estabelecimento dos fluxos para o atendimento 29,30. Entretanto, existem muitos obstáculos para isso, incluindo a ausência de unidades de saúde de referência e a falta de capacitação dos profissionais de saúde 6.

(P53): "Quantas pessoas terão que morrer ainda, para o governo tomar postura sobre a doença celiaca!! Capacitar os profissionais de saúde para realizar diagnóstico rápido e eficaz...".

Conviver anos a fio com sintomas, peregrinar de consultório em consultório, colecionar resultados de exames que não esclarecem o diagnóstico e sentir-se cronicamente doente faz com que muitas pessoas comecem a buscar soluções alternativas. Nessa busca, não são poucos os relatos dos que optaram por excluir o glúten por conta própria. 
Observa-se, também, resistência por parte dos médicos em solicitar os exames para diagnóstico, seja porque ainda consideram as DRG raras ou exclusivas da população infantil ou, ainda, por acreditarem se tratar da "moda" da dieta sem glúten, principalmente quando o paciente não apresenta diarreia ou perda de peso. Em outras situações, os exames são solicitados, porém os profissionais não informam sobre a necessidade de estar consumindo glúten para realizá-los ou pedem apenas os exames sorológicos, dispensando a endoscopia com biópsia, contrariando o PCDTDC 29,30,31.

(P56): “... a minha mãe tem 68 anos (...) fez os sorologicos e deram negativos e com exames negativos dificilmente se pede a biopsia porque não tem indícios da celíaca”.

(P19): “...gastro endoscopista que já fez 7 endoscopias minhas virou e disse: não você não tem isso, não surta com o glúten. Mas pergunta se alguma dessas vezes ele fez a biopsia do duodeno?! Nunca! Eu que pedi porque li sobre isso e fui atrás".

Em geral, as pessoas vivem muitos anos com sintomas das DRG antes de serem diagnosticadas. Essa realidade tem consequências sérias para a saúde dessas pessoas, como alterações neurológicas, osteoporose, infertilidade, doença celíaca refratária e câncer 30. Em estudo realizado com mulheres celíacas no Paraná 32, 77\% das participantes relataram que seu diagnóstico foi tardio, embora 38\% delas apresentassem sintomas desde a infância. Como consequência da demora desse diagnóstico, elas referiram o aparecimento de alterações tireoidianas, depressão, anemia, dores articulares, má absorção de nutrientes, perda de peso e linfoma.

\section{As fragilidades no cuidado em saúde}

A dificuldade de obter um diagnóstico gera o sentimento de incompreensão, invisibilidade e indignação nas pessoas com DRG, pois se sentem doentes (illness, perturbação, mal-estar, desconforto sentido pelo paciente) em função do sofrimento, da dor e do mal-estar associados à ingestão de glúten, mas os médicos não identificam a doença (disease, alterações patológicas ou lesões em órgãos ou sistemas, capazes de serem vistas ou mensuradas por exames) se ela não estiver "visível", com sinais claros como as feridas da dermatite herpetiforme ou a desnutrição intensa da doença celíaca clássica 20,21. Relatos semelhantes foram encontrados nos trabalhos de São Bento \& Moreira 8,9 com mulheres com endometriose, cuja dor, muitas vezes incapacitante e com grandes prejuízos à qualidade de vida, não pode ser quantificada.

Nas DRG, é possível identificar alterações histológicas (disease) na doença celíaca assintomática, mesmo com grave comprometimento da superfície absortiva intestinal e má absorção de vários nutrientes. Nesses casos, a doença não é percebida por aqueles que apresentam essa condição. Por outro lado, pessoas com sensibilidade ao glúten não celíaca e doença celíaca não diagnosticadas vivenciam o sofrimento e, frequentemente, sentem-se muito doentes ou com diversos sintomas e desconfortos (illness) sem que os exames - não apropriados ou realizados de forma equivocada - apresentem qualquer tipo de alteração.

As DRG são condições sistêmicas, com manifestações em diversas partes do corpo e, sem um olhar holístico, ficam prejudicadas a avaliação clínica e a compreensão acerca dos impactos emocionais, na vida social, familiar e profissional do paciente. Muitas pessoas saem dos consultórios com a sensação de que não foram acolhidas nem ouvidas, que suas queixas não foram valorizadas e que foram desrespeitadas:

(P28): "Fui ao dermatologista hoje e ele veio me dizer que intolerância a glúten e à lactose não existe, e ficou dando risada da minha cara e ainda disse que se existir é só em crianças e o máximo que pode dá é uma dor de barriga e dor de barriga não mata ninguém (...). Ele disse que eu era muito estressada porque me recusei a ouvir o que ele estava dizendo".

O modelo biomédico, centrado na doença e não no doente, ao se fundamentar nos meios diagnósticos para evidenciar lesões e doenças, acabou por se afastar do ser humano sofredor, como "totalidade viva” e fez com que o diagnóstico substituísse a atenção e o cuidado integral e humanizado à saúde 15,16,17,19,20,21,33,34, impondo o saber médico intelectualizado e tecnicista, desconsiderando os saberes do paciente e a sua realidade, gerando uma condição de subordinação na relação médico-paciente 19.

Em relação à sintomatologia e ao quadro clínico, percebe-se também que há um prejulgamento baseado apenas na aparência dos pacientes. Se eles não apresentam elementos objetivos que expres- 
sem a presença de uma doença, como desnutrição e relatos de diarreia, suas queixas não são consideradas como doenças "reais" (disease), sendo interpretadas como problemas "psicológicos".

(P36): "Senti nesta segunda uma fadiga extrema e dores abdominais. Fui ao clínico geral (...) pois estava me sentindo muito mal. Quando falei que sofria de sensibilidade ao glúten ele caçoou da minha cara, foi grosso. Disse que doença celíaca causa emagrecimento e o diagnóstico é na infância, e eu não sou magra e tenho 28 anos. Tentei rebater, mas ele foi muito grosseiro. Me senti humilhada".

Além disso, percebe-se que as queixas femininas, geralmente mais subjetivas e detalhadas, tendem a ser menos valorizadas que as queixas masculinas, mais pontuais e objetivas. Muitas mulheres apresentam sintomas de origem neurológica, com alterações de humor e das emoções, além dos impactos na saúde reprodutiva frequentemente descobertos tardiamente.

(P37): "...é muito difícil ficar alegre com a dermatite herpetiforme ativa. Então você toma Prozac e remédios que só fazem você empurrar com a barriga, mas que não cortam o mal pela raiz”.

Quando nenhuma causa física é encontrada, o fato é considerado como psicossomático ou psicogênico 22. Assim, frequentemente, as mulheres são encaminhadas para os profissionais de saúde mental sem que tenham feito os exames necessários ao diagnóstico das DRG. Muitas passam anos sendo tratadas com psicotrópicos, sem grande melhora. Entretanto, relatam melhora dos sintomas, diminuição das doses dos medicamentos ou mesmo suspensão deles após iniciarem a dieta de exclusão de glúten:

(P39): "Eu tive ansiedade e pânico. Iniciou em 2004... fiz vários tratamentos e as crises sempre voltavam... em março desse ano iniciei um novo tratamento... e o remédio não fazia efeito mesmo com a dose dobrada... ao descobrir a doença celíaca retirei o glúten e não sinto mais nada... estou ótima... o psiquiatra só disse que foi coincidência... mas pra mim não foi".

O descaso com as queixas femininas pode ocorrer em função do desconhecimento de o quanto a inflamação crônica interfere nas vias metabólicas, ocasionando alterações na produção de neurotransmissores, gerando alguns sintomas neurocomportamentais dentro do espectro das DRG 1.

Na sensibilidade ao glúten não celíaca, mesmo não havendo lesões visíveis na mucosa intestinal nem havendo alterações nos marcadores sorológicos, os indivíduos sentem-se constantemente doentes. O mesmo ocorre com celíacos, que, apesar de apresentarem tais alterações, desconhecem a causa de seus sintomas, pois os exames corretos nunca foram solicitados, então, para todos os efeitos, eles "não têm nada".

(P25): "Aqui no grupo as histórias se repetem: você é hipocondríaca, você tem doença psicossomática, você tem intolerância à lactose, você [tem] síndrome do intestino irritável, você tem tudo, menos doença celíaca... e é doença celíaca".

Por outro lado, há uma corrente entre profissionais de saúde que preconiza a exclusão do glúten indiscriminadamente com base na crença de que essa proteína seria prejudicial a todas as pessoas. Essa exclusão ocorre sem a solicitação prévia de exames para diagnóstico e sem orientação sobre cuidados com a contaminação cruzada e acabam também dificultando o diagnóstico das DRG.

(P42): "Tenho Hashimoto e doença celíaca, mas meu endocrinologista disse que todas as pessoas que fazem tratamento na tireoide devem parar com o glúten, pois afeta o funcionamento da mesma, independente de ser celíaco ou não".

As fragilidades no cuidado em saúde das pessoas com DRG são inúmeras, mas talvez a situação mais crítica experimentada no seu contato com o sistema de saúde seja a insegurança alimentar e nutricional, quando necessitam de internação hospitalar. São recorrentes as queixas de acidentes com alimentos contaminados ou dietas trocadas/incorretas, contendo pães, biscoitos, macarrão. $\mathrm{O}$ hospital, local que deveria garantir a recuperação da saúde, acaba se tornando um local de risco de agravamento dos sintomas.

(P67) “...eu fiz uma cirurgia também. Ganhei pulseira de alérgico, mas no lanche veio pão francês. Quando lembrei a eles que eu era celíaca mandaram um pão de queijo da lanchonete. Não comi, pois, imaginei que estava na mesma estufa dos salgados...".

(P73): "Apesar de receber a visita de 5 nutricionistas, as beldades continuaram a encaminhar no café da manhã iogurte com aveia, mingau de aveia, biscoitos cream cracker, torradas".

Essa situação se agrava quando, além de o hospital não ter condições de oferecer alimentação segura, os pacientes e familiares são proibidos de entrar com alimentos sem glúten, devido às normas 
de segurança microbiológica. Pelo modelo biomédico de cuidado em saúde, sendo o hospital sua expressão máxima, pacientes e seus familiares se sentem "diminuídos” na presença de um profissional 19,22,35 e não se sentem capazes de argumentar quando detectam que algo está errado.

(P70): “...sou só uma mãe, com segundo grau, dentro de um hospital discutindo com gente formada (e mal informada). Brigar dentro de um consultório é uma coisa, mas brigar com um hospital já é outros 500 e não estou preparada, estou com medo...".

A exposição ao glúten, seja por contaminação cruzada ou por consumo de alimentos inadequados ao quadro clínico, aumenta o risco de agravamento da doença que motivou a internação e do tempo de permanência no hospital, além de todo o estresse e impacto emocional que a situação pode causar. Por esse motivo, muitos participantes do grupo já se antecipam e buscam informações sobre como proceder durante a internação para minimizar os riscos. Mas isso não é suficiente para resolver os problemas enfrentados.

A ausência de escuta dos pacientes e de seus familiares, além de produzir mais sofrimento e angústia para pessoas que já estão internadas, prejudica a intervenção técnica e a qualidade dos cuidados em saúde 36. A humanização em saúde pressupõe a troca de saberes, por meio do diálogo entre os pacientes e suas famílias e os profissionais 35 , possibilitando aumentar a segurança clínica e a qualidade dos cuidados em saúde 36 .

\section{O grupo Viva Sem Glúten como rede de apoio}

Diversos estudos já mostraram que os laços sociais exercem grande influência sobre a saúde e sobre a adaptação em situações de estresse e doença e, também, que a inexistência ou fragilidade desses aumenta os riscos de adoecimento e morte 20,37. Esses laços constituem o que se denomina de rede social de apoio (ou apoio social), formada por aqueles com quem a pessoa "pode contar", independentemente de consanguinidade, ou seja, podem ser estabelecidos com amigos, colegas de trabalho ou de estudo, vizinhos, conhecidos ou mesmo pessoas que fazem parte de um mesmo grupo, como os grupos religiosos e grupos ou associações de pessoas que partilham de uma mesma condição clínica 37.

A participação em tais grupos, inclusive em grupos de apoio virtuais, promove interação e troca de informações e favorece o empoderamento dos indivíduos e maior autonomia das famílias frente ao cuidado em saúde, preenchendo uma lacuna deixada pelos serviços de saúde e seus profissionais.

Com a popularização da Internet, houve uma ampliação do acesso às informações sobre DRG, possibilitando o surgimento de um novo perfil de pacientes, o "paciente informado" 38. Trata-se de uma pessoa que, a partir do melhor entendimento de sua condição clínica, desenvolveu habilidades para desempenhar um papel ativo na gestão de sua própria saúde, sendo capaz de transformar a relação médico/paciente tradicional do modelo biomédico. Além da própria experiência com sua condição clínica, o acesso à informação, por meio da consulta a sites de profissionais de saúde, universidades e centros de pesquisa, blogs e revistas eletrônicas e a facilidade de trocar informações com outras pessoas favorecem maior autonomia em relação ao próprio cuidado 38.

Grupos como o VSG se constituem como espaços de apoio social, de acolhimento, fonte de informações confiáveis e orientações e, principalmente, como rede de solidariedade entre pessoas que, muitas vezes, nunca se viram pessoalmente, contribuindo para a informação e o fortalecimento dos pacientes 6,28. O grupo VSG caracteriza-se como a principal fonte de apoio social, o local onde as pessoas com DRG se sentem acolhidas, ouvidas, amparadas, orientadas. É o espaço onde acontece o empoderamento dessas pessoas e de onde saem muitas iniciativas em prol da melhoria da qualidade de vida, e grande parte disso tudo se deve trabalho voluntário da moderação.

(P25): "Fico aqui pensado como eu queria ter podido acessar o conhecimento das pessoas deste grupo, quando tive o meu diagnóstico...".

É a partir da participação no grupo que muitas pessoas tomam conhecimento dos sintomas associados às DRG, informam-se a respeito dos exames corretos para obtenção do diagnóstico e sobre quais profissionais procurar. Nele, elas vivenciam os sentidos de pertencimento e de identidade, pois encontram outras pessoas em situação semelhante. Desenvolvem laços de solidariedade, de reciprocidade e de amizade e se sentem mais fortalecidas e esperançosas. A fala de uma das moderadoras do grupo VSG também expressa sua percepção a respeito da importância do grupo para as pessoas com DRG e seus familiares: 
(P76): "Num mundo ideal, onde os médicos conhecem doença celíaca e são experientes diagnosticistas, não precisamos estudar, nos reunir em grupos de acolhimento e informação nem desconfiar de nada. Infelizmente precisamos muito do grupo, da experiência coletiva e de estudo constante para manejarmos os problemas que enfrentamos".

\section{Considerações finais}

As postagens e comentários analisados trouxeram à tona a invisibilidade e negligência envolvendo as DRG, tanto em relação ao diagnóstico quanto ao tratamento, em situações em que a pessoa está em risco alimentar, nutricional e até de adoecer e morrer por complicações causadas pelo diagnóstico tardio. Além disso, foi possível perceber o quanto ambas, invisibilidade e negligência, impactam negativamente a vida das pessoas com DRG.

A peregrinação e a demora em conseguir orientação e tratamento adequado são frequentes, apontando para a urgência na busca por soluções. É necessário dar voz a tantas pessoas e suas histórias de sofrimento e peregrinação, olhando para todas as questões que permeiam o cuidado em saúde, o tradicional modelo biomédico, a hierarquia "médico-paciente" e a humanização do cuidado.

Os achados deste estudo ajudam na identificação de diferentes fragilidades no cuidado das pessoas com DRG, envolvendo as dificuldades no acesso aos serviços de saúde, a (in)segurança alimentar e nutricional, a invisibilidade das pessoas e seu sofrimento, sobretudo em relação às mulheres. Para superar esse cenário, é necessário desenvolver estratégias que sensibilizem e despertem o interesse dos profissionais de saúde e ampliem seu conhecimento técnico nessa temática para que possam reconhecer as DRG e suas manifestações, saibam fazer o diagnóstico e possam promover o cuidado em saúde de forma integral e multidisciplinar. É preciso, também, organizar uma rede de cuidado às pessoas com essa condição. A publicação de duas edições do PCDTDC foi um passo fundamental (mas não suficiente) nessa direção. São imprescindíveis ações voltadas para sua divulgação nas universidades e para sua implementação efetiva na rede pública de atenção à saúde.

Por fim, vale ressaltar a necessidade da realização de estudos voltados ao cuidado em saúde, em todas as suas nuances, incluindo aqueles de avaliação de implementação e de efetividade de ações desenvolvidas no SUS. São também relevantes pesquisas que se dediquem a aspectos relativos à segurança alimentar e nutricional, para além dos referentes à produção e ao valor nutricional de alimentos sem glúten. Destaca-se ainda a necessidade de estudos que aprofundem a análise com a perspectiva de gênero nas relações envolvidas no cuidado em saúde. 


\section{Colaboradores}

J. Crucinsky participou do estudo desde sua concepção até a apresentação dos resultados; conduziu a pesquisa de campo, realizou a análise do material empírico e redigiu o manuscrito. J. J. Damião e I. R. R. Castro participaram do estudo desde sua concepção até a apresentação dos resultados, supervisionaram a pesquisa de campo, apoiaram a análise do material, participaram da escrita e revisão crítica do manuscrito.

\section{Informações adicionais}

ORCID: Juliana Crucinsky (0000-0003-24910300); Jorginete de Jesus Damião (0000-0001-65913474); Inês Rugani Ribeiro de Castro (0000-00027479-4400).

\section{Referências}

1. Al-Toma A, Volta U, Auricchio R, Castillejo G, Sanders DS, Cellier C, et al. European Society for the Study of Coeliac Disease (ESsCD) guideline for coeliac disease and other glutenrelated disorders. United European Gastroenterol J 2019; 7:583-613.

2. Byass P, Kahn K, Ivarsson A. The global burden of childhood coeliac disease: a neglected component of diarrhoeal mortality? PLoS One 2011; 6:e22774.

3. Peña AS, Rodrigo L. Epidemiology of celiac disease and non-celiac gluten-related disorders. In: Arranz E, Fernández-Bañares F, Rosell CM, Rodrigo L, Peña AS, editors. Advances in the understanding of gluten related pathology and the evolution of gluten-free foods. Barcelona: Omnia Science; 2015. p. 2773.

4. Mendes FBR, Hissa-Elian A, Abreu MAMM, Gonçalves VS. Review: dermatites herpetiformis. An Bras Dermatol 2013; 88:594-9.

5. Barbosa ASS, Conceição JS, Silva LR. Conhecimento dos pediatras sobre doença celíaca: estudo piloto. Rev Ciênc Méd Biol 2010; 9:2934.

6. Paula FA, Crucinsky J, Benati R. Fragilidades da atenção à saúde de pessoas celíacas no SUS: a perspectiva do usuário. Demetra (Rio J.) 2014; 9 Suppl 1:311-28.

7. Bai JC, Ciacci C, Corazza GR, Fried M, Olano C, Rostami-Neiad M, et al. World Gastroenterology Organization Global Guidelines. Doença celíaca. https://www.worldgastroen terology.org/UserFiles/file/guidelines/celiacdisease-portuguese-2016.pdf (acessado em 17/ Jun/2020).

8. São Bento PAS, Moreira MCN. A experiência de adoecimento de mulheres com endometriose: narrativas sobre violência institucional. Ciênc Saúde Colet 2017; 22:3023-32.

9. São Bento PAS, Moreira MCN. Quando os olhos não veem o que as mulheres sentem: a dor nas narrativas de mulheres com endometriose. Physis (Rio J.) 2018; 28:e280309.

10. Kozinetz RV. Netnografia: realizando pesquisa etnográfica online. Porto Alegre: Penso; 2014.

11. Mercado LPL. Pesquisa qualitativa online utilizando a etnografia virtual. Revista Teias 2012; 13:169-83.

12. Bardin L. Análise de conteúdo. São Paulo: Edições 70; 2011.

13. Minayo MCS. O desafio do conhecimento: pesquisa qualitativa em saúde. São Paulo: $\mathrm{Hu}-$ citec Editora; 2014.

14. Merhy EE. A perda da dimensão cuidadora na produção da saúde. In: Merhy EE, organizador. O Sistema Único de Saúde em Belo Horizonte: reescrevendo o público. Belo Horizonte: Xamã; 1998. p. 103-20.

15. Pinheiro R, Mattos RA. Cuidado: as fronteiras da integralidade. 3a Ed. São Paulo: Hucitec Editora/Rio de Janeiro: Instituto de Medicina Social, Universidade do Estado do Rio de Janerio/Associação Brasileira de Saúde Coletiva; 2005. 
16. Ayres JRCM. Cuidado: trabalho e interação nas práticas de saúde. Rio de Janeiro: Centro de Estudos e Pesquisa em Saúde Coletiva, Instituto de Medicina Social, Universidade do Estado do Rio de Janeiro/Associação Brasileira de Saúde Coletiva; 2009. (Coleção Clássicos para Integralidade em Saúde).

17. Deslandes SF, Mitre RMA. Processo comunicativo e humanização em saúde. Interface (Botucatu) 2009; 13 Suppl 1:641-9.

18. Malta DC, Merhy EE. O percurso da linha do cuidado sob a perspectiva das doenças crônicas não transmissíveis. Interface (Botucatu) 2010; 14:593-606.

19. Demétrio F, Paiva JB, Fróes AAG, Freitas MCS, Santos LAS. A nutrição clínica ampliada e a humanização da relação nutricionista-paciente: contribuições para reflexão. Rev Nutr 2011; 24:743-63.

20. Cassel J. An epidemiological perspective of psychosocial factors in disease etiology. Am J Public Health 1974; 64:1040-3.

21. Cassell EJ. The healer's art: a new approach tothedoctor-patient relationship. Philadelphia: Lippincott; 1976.

22. Helman CG. Saúde, cultura e doença. 5a Ed. Porto Alegre: Artmed Editora; 2009.

23. Alves PC. Itinerários terapêuticos e os nexus de significados da doença. Revista de Ciências Sociais 2015; 42:29-43.

24. Ferreira J, Espírito Santo W. Os percursos da cura: abordagem antropológica sobre os itinerários terapêuticos dos moradores do complexo de favelas de Manguinhos, Rio de Janeiro. Physis (Rio J.) 2012; 22:179-98.

25. Valdanha-Ornela ED, Santos MAO. Percurso e seus percalços: itinerário terapêutico nos transtornos alimentares. Psicol Teor Pesqui 2016; 32:169-79.

26. Daniel JMP, Cravo VZ. Valor social e cultural da alimentação. In: Canesqui AM, Garcia RWD, organizadores. Antropologia e nutrição: um diálogo possível. Rio de Janeiro: Editora Fiocruz; 2005. p. 57-68.

27. Bandeira LM, Pertulam RB. As pesquisas sobre uso do tempo e a promoção da igualdade de gênero no Brasil. Rio de Janeiro: EdUerj; 2016.

28. Paez AS, Moreira MCN. Sobre a performance de sofrimento na web: narrativas de mães de crianças com condições crônicas complexas de saúde em uma revista eletrônica. Physis (Rio J.) 2019; 29:e290104.
29. Ministério da Saúde. Portaria no 307, de 17 de setembro de 2009. Diário Oficial da União 2009; 18 set.

30. Ministério da Saúde. Portaria no 1.449, de 11 de novembro de 2015. Aprova o Protocolo Clínico e Diretrizes Terapêuticas da Doença Celíaca. Diário Oficial da União 2015; 12 nov.

31. Brasil. Doenças raras ainda representam desafio para saúde pública. http://www.brasil.gov. $\mathrm{br} /$ saude/2015/03/doencas-raras-ainda-repre sentam-desafio-para-saude-publica (acessado em 20/Jan/2018).

32. Santos AS, Ribeiro CSG. Percepções de doentes celíacos sobre as consequências clínicas e sociais de um possível diagnóstico tardio na doença celíaca. Demetra (Rio J.) 2019; 14 Suppl $1: e 33310$.

33. Ferreira LR, Artmann E. Discursos sobre humanização: profissionais e usuários em uma instituição complexa de saúde. Ciênc Saúde Colet 2018; 23:1437-50.

34. Kalichman AO, Ayres JRCM. Integralidade e tecnologias de atenção à saúde: uma narrativa sobre contribuições conceituais à construção do princípio da integralidade no SUS. Cad Saúde Pública 2016; 32:e00183415.

35. Mota RA, Martins CGM, Véras RM. Papel dos profissionais de saúde na política de humanização hospitalar. Psicol Estud 2006; 11:32330.

36. Anguita MV, Sanjuan-Quiles A, Ríos-Risquez MI, Valenzuela-Anguita MC, Juliá-Sanchis R, Montejano-Lozoya R. Humanização dos cuidados de saúde no serviço de urgência: análise qualitativa baseada nas experiências dos enfermeiros. Referência 2019; serIV:59-68.

37. Andrade GN, Panza AP, Vargens OMC. As redes de apoio no enfrentamento do câncer de mama: uma abordagem compreensiva. Ciênc Cuid Saúde 2011; 10:82-8.

38. Pereira Neto A, Barbosa L, Silva A, Dantas MLG. O paciente informado e os saberes médicos: um estudo de etnografia virtual em comunidades de doentes no Facebook. Hist Ciênc Saúde-Manguinhos 2015; 22 Suppl:1653-71. 
Abstract

Gluten-related disorders affect $1 \%$ to $6 \%$ of the population, with complications and high risk of short and long-term morbidity and mortality. Since 2009, Brazil has a Clinical Protocol of Therapeutic Guidelines for Celiac Disease, but there are frequent complaints by persons with gluten-related disorders concerning the lack of healthcare professionals' knowledge of this topic and the difficulties related to healthcare, for both diagnosis and treatment. This study aimed to understand the weaknesses in healthcare perceived by persons with gluten-related disorders. An online qualitative survey was conducted in the Living Without Gluten group on Facebook, consulting the records saved by the group for 65 months, which totaled 510 posts and the respective comments. The data were grouped in categories, and thematic content analysis was performed, adopting the theoretical references on healthcare. The analysis revealed that the searches for diagnosis and adequate treatment were often described as a forced pilgrimage, resulting from shortcomings in healthcare, including lack of up-to-date knowledge on gluten-related disorders among the healthcare professionals and problems in the physician-patient relationship. Weaknesses in patient care and late diagnoses contribute to increasing the risk of complications and deaths. In this context, the Living Without Gluten group plays a leading role as a support group and network of solidarity, favoring increased awareness and empowerment of numerous Brazilians with gluten-related disorders.

Qualitative Research; Physician-Patient Relations; Self-Help Groups

\section{Resumen}

Los desórdenes relacionados al gluten afectan de $1 \%$ a $6 \%$ de la población, con complicaciones y alto riesgo de morbimortalidad en corto y largo plazos. Desde 2009, Brasil posee un Protocolo Clínico de Directrices Terapéuticas para la Enfermedad Celíaca, sin embargo, son comunes las quejas de las personas con desórdenes relacionados al gluten, respecto a la falta de conocimiento de los profesionales de salud en esa temática y las dificultades relacionadas con el cuidado en salud, en relación tanto con el diagnóstico como con el tratamiento. Este estudio se marcó como objetivo comprender las fragilidades en el cuidado en salud percibidas por personas con desórdenes relacionados al gluten. Se realizó una investigación cualitativa virtual en el grupo Vivir Sin Gluten (VSG) de la red social Facebook, en la que se consultaron los registros almacenados en el grupo durante 65 meses, que totalizaron 510 posts y sus respectivos comentarios. Los datos se agruparon en categorías y se realizó un análisis temático de contenido, adoptándose los referenciales teóricos sobre el cuidado en salud. El análisis reveló que las búsquedas de un diagnóstico y tratamiento adecuado frecuentemente se describen como una peregrinación, siendo derivados de las fragilidades en el cuidado en salud, traducidas por la falta de conocimiento actualizado de los profesionales sobre las desórdenes relacionados al gluten y por problemas en la relación profesional-paciente. Las fragilidades en el cuidado en salud y los diagnósticos tardíos contribuyen a aumentar el riesgo de complicaciones y óbitos. En este contexto el grupo VSG se destaca en su papel de grupo de apoyo y red de solidaridad, favoreciendo la información y el empoderamiento de innumerables personas con desórdenes relacionados al gluten.

Investigación Cualitativa; Relaciones

Médico-Paciente; Grupos de Autoayuda
Recebido em 20/Dez/2019

Versão final reapresentada em 04/Jul/2020

Aprovado em 20/Jul/2020 